\title{
Do we need a second engine for Entrepreneurship? How well defined is intrapreneurship to handle challenges during COVID-19?
}

\author{
Mehmet Kiziloglu ${ }^{1 *}$, and Samrat Ray $^{2}$ \\ ${ }^{1}$ Pamukkale University, Turkey \\ ${ }^{2}$ Peter the Great Saint Petersburg Polytechnic University, Russia
}

\begin{abstract}
Changing domains of economic mobility has brought in perspectives of innovation which are quite different from the earlier traditions in the so-called readings of Schumpeterian ways of innovative thinking. The new pandemic has taught us lessons that multidisciplinary innovation is not constrained to some mystical black box of innovation but should be elastic and accessible based on necessity and choices. Human beings are not always rational. Cognitive biases and nudges arising out of crisis globally has shown behavioral functionalities which changes the way human beings react and succumb to decision-making. This particular paper is based on extensive literature reviews and global cases arising out of extregencies and the subsequent development of field experiments which study the effects of various factors on innovation within the company. The filed experiments conducted were at national level in cooperation with national chamber of commerce wherein both intrinsic and extrinsic values of economics of scale was studied statistically using advanced techniques to not only analyze the results but infer on earlier research gaps in factors influencing the innovation blackbox of intrapreneurship which takes into account the psychology of economic decision making inside the corporate bandwagon. The rational choice behind measuring intrapreneurship in this study is impactful for learning the trends of human actions and behavior in a firm, which can be a yardstick for future academicians and policymakers to implement directly for aggravating the incubation indices.
\end{abstract}

\section{Introduction}

History has never been so kind enough pertaining to judging motivation, support structure and entrepreneurial ecosystem in creating a new world inside innovation box which can totally change how and when companies globally react to extrigencies happening out of various calamities; recent being the Covid-19 pandemic which is still creating mass scale destruction to human life and growth in emerging economies. Global polymath has been

\footnotetext{
* Corresponding author: mkiziloglu@pau.edu.tr
} 
drastic, and it has taught hard-hitting dialects to global economists whether it has been the dearth of entrepreneurial innovation outside the company or the necessity to innovate from within. Global changes have been drastic during the COVID-19 pandemic when the entrepreneurial pursuits were viewed as being different in context in different regions across the globe with respect to various indicators to innovation. Open innovation funnel has been quite challenging wherein the nexus between government and intuitional reforms have seen the birth of various forms of entrepreneurship and growth models of economics. There lies various challenges to the world of economics today! Not to speak of the dynamics of poverty and inequality which is the sin creator from generations and in itself bears testimony to huge research gaps with the failure of the dynamics of democratic policies and governance to tackle poverty and illusions of hunger and misjustice. On the contrary policy makers globally are faced with retrospective choices to succumb to national policies without innovating from within. There often lies the mystery of innovating and thinking from within the box where not only entrepreneurship acts as economics of growth and development but can cater to various philosophies of reprieve and judgments. When the global community burns out of despair and inhuman conditions arising from the crisis points during the COVID-19 pandemic mere theoretical judgments are not enough to feed the hungry or bring justice to the torn and scorched. Various economic fallacies and fragile innovative channels have seen the policy of national governments moving away from the inside story of innovation to a glossier picture which is not only detrimental to human development but creates a mirage to economic growth paradox. It not only caters to the necessity for improvements in thought process but nurturing and improving the behavioral heuristics of innovation channels. Globally the buzzword has shown various forms of entrepreneurship which can cater to social justice theories and upliftment of women in general, but few have seen the rise of titans in intrapreneurial activities. Even the economics of growth has surpassed such terminologies which can be a boon to the development of not only the big firms but also play great role at the grassroots levels including the bottom of the pyramid. It is worth mentioning that intrapreneurial activity can play a pivotal role inside the creativity indexes of social entrepreneurship which is not only taking care of the masses inside the poverty trap but also to the overall development of a nation. There lies a vast literature before us pertaining to the various myriads of entrepreneurial innovation but very few have chosen the beaten path of thinking from within and has earmarked intrapreneurship activity which recent researchers say can be a big boon to the growth engines for poverty alleviation. The conjunction path is at one point fighting the terror of poverty and other is the menace arising out of the pandemic which has seen millions of death globally in an unforeseen strategic collapse and increasing unemployment over a decade of suffering. The necessity arising out of the study for psychological imperatives for decision making in case of not only entrepreneurship but also the logistics of intrapreneurship has been studied wherein the childhood imperatives and family business innovation has brought in novel concepts to the engines of intrapreneurial thoughts [4]. There needs to be a change in thought process wherein it needs to be understood that big and small firms cannot behaviorally act in parlance to entrepreneurial activity chains of growth [5]. Chesbrough (2003) has stated about the necessity for exogenous models of innovation not merely confined but creating a paradigm shift for intrinsic innovative mobility within firms. Pinchot, 1985 has furthered the variances of entrepreneurial capacity building, ambiances over retrospective analytics in intrapreneurial thought processes which gives impetus to the growth channels. Here the managerial competency building has shown greater impetus to innovation funnel improvements which can lead to overall entrepreneurial activity of a firm. From the time frame of coinage of the term "Intrapreneurship" by Gifford Pinchot III, various management gurus and strategists have tried to remodel the existential necessity behind the metaphor depending on circumstances but very few have succeeded to create the strategic imperatives that intrapreneurial activity just like Richard Branson's thought as the 
little brother has created a vast failure in judging its importance in management and economic parley [7]. Learning curves arising from the days of $3 \mathrm{M}$ and Xerox corporation wherein intrapreneurial activity created baby booms in innovation, Google, Microsoft and Bell Labs have come a long way in nurturing a entity in itself "The Intrapreneurial bandwagon"; wherein the employees thrive and develop their ideas and actions for self-growth and growth of the firm. It is obvious that a systematic catering of literature review is necessary but historical data and analyses are very much important to understand the nature and intrinsic behavioral psychology behind management practices in intrapreneurial challenges arising inside the blackbox of technological advancements in global corporations. Very important likewise is the strategic imperatives of firms historically set at the backdrop of recession and inflationary measures to the very recent economic crash coming out of the pandemic situation. It is likewise noteworthy that behavioral motivation and challenges are quite different in emerging economies with respect to advanced western countries in dealing with social entrepreneurship and innovation which can drive out hunger and inequality. The paradox of inequality is so widespread and has branches into various economic foundations that management strategy to implement innovation functionaries inside firm level is quite challenging and requires considerable inside venturing and incubation. The freedom to choose paradox inside the strategy of firms have changed requiring thorough analysis with respect to how people react to changing environments inside a firm? [8] How positive are the laggards in innovation? Are people quite rational in choosing to be intrapreneurial? How can best practices in $\mathrm{Hr}$ be implemented to recruit and train? Can people be natural pullers of innovation? These are few pertinent questions which are very important to understand so that a small as well as a big firm can capitalize growth infrastructure [9]. There lies a underlying mystery behind opening the innovation box inside a firm as there are various factors which are necessity towards the creativity unleashing inside the firm during crisis situations like COVID-19. The pandemic bears devastating stories of death and despair arising out of panic, economic crashes both at national levels and institutional imbalances brought about by impoverished living conditions in merging countries which are fighting every day the fallouts of hunger, poverty and migration. The global heterogeneity in poverty is in itself a push factor for inter firm as well as intra firm level innovation which saw rise of multidisciplinary research activity which are impactful to bring about relief measures to logistics of poverty alleviation. Recent advancement in logistics of vaccine delivery has shown intrapreneurial challenges in humanitarian perspectives in poorer countries globally where improper corporate cultures are big hindrances to intrapreneurial sprout shoots. The germ lings of economic growth has seen a backward mobility in relatively poorer nations as is compared to massive industrialization post the depression years in even American subcontinent wherein Keynesian monetary policies has governed the national policy planning with respect to labour welfare and institutional value judgments [10]. It is important in that respect that values and ethics play a good role in nurturing a firm and also creates an impulse towards how well the employees behave and are creative in idea generations. Such factors also move in to creating growth outputs to firms and capacity building during the pandemic period. The patterns of poverty and how poor people react are necessary yardsticks to planning intrapreneurial incubation in few organizations in emerging economies. In such scenario, well advanced measurement indices pertaining to financial heuristics are also important to understand how and when people react to decision making inside a firm. Such spillovers can be technological or behavioral in context wherein general ecosystem can be studied at ease to understand rationality of choices and behaviors [11]. The bluebook of $\mathrm{Hr}$ best practices has changed so as the organizational behavior has evolved through economic evolution. Technology has penetrated deep inside the firm wherein adaptive behaviors have changed expectations and reduced delivery lifecycles. At this festive moment of success, lies proper planning and strategy building with respect to business intelligence which can not only be studied with 
respect to data analytics but also by mapping future trends and historical databases [12]. From another millennial story post 1980 to Time Magazine bound "Intrapreneurial" forefront analysis this particular period saw massive innovation and changes in quality control and employee management inside the firm with the profit machine case study of GE under the leadership of Jack Welch to Steve Jobs the Shrunk work episode is worth mentioning [13]. As per Chong (2003) non-economic determinants are also important judgmental factors so as is the revenue creation (Miller et al,2008) and customer feedback mechanism wherein innovation is portrayed (Leseure et al. 2001). Lucas as well as Romer has pointed towards human capital being a more retrospective avenue which brings accelerated economic growth (Mankiw et al.1992)(14).Educating the labour force also gives impetus to social capital generation (Coleman 1988).Subramanian(2017) points towards personality traits of individuals and balances the charisma of founders of respective institutions in creating growth(15). Hsu (2016) noted the emergence of social and human capital in expectation to venture led success stories which determines the quality of economic activity within the firm. Dess and Picken (1999) highlight the organizational capital structure underlying few basic parameters like a) Reporting mechanism b) Design making inside firm c) System allocation d) Organizational leadership patterns (16). IWB portrays how individualistic behavioral patterns create changes within organizations. IWB has a distinct positivity relation with respect to institutional performances as studied by various researchers like Rexhepi and Berisha (2017). According to Woodman et al. innovative functionaries within institutions not only identify new ideas but also nurture creativity. De Jong (2007) identifies innovative work behavior (IWB) as innovation-based idea creation at individual level for respective unit and organization. Hurt et al. has promulgated the newer dimensions to individual innovative behavior and linked it to personality functionaries. Bass (1985) states on organizational leadership as a yardstick for bringing in revolutionary changes in its followers on transformational basis based on self-interest and guided by changing morals and values [7]. Kinicki (2000) reacts to negativity in behavior of employee which can create in itself a negative bias towards organizational productivity. Peus et al. brings out the fallacy of fear to fail as a criterion for not changing the way things work and innovate [18]. But we have to believe that the global community is changing, and the winning trophy lies with bringing innovation to market (Ramadani et al. 2019). Here comes the particular definition of strategic entrepreneurship taking strategy to innovate (Hitt et al. 2001) [19]. Obviously human capital is an integral part of strategy led innovation (Ireland et al.2003) [20]. Porter (1980) has concluded on creating competitive advantages in relation to stake holder benefits. The meaning of various forms of entrepreneurship catering to social inclusion has been well studied wherein the various pillars of the bottom $4 \%$ has been well catered to [21]. Various natural calamities and growth paradoxes have arisen out of necessity which changes human rationality towards economic decision making. Social injustices and natural calamities like famines create great impetus to poverty and generates wide scale unemployment. Such behavioral changes create newer grounds to innovation hotbeds (Amartya et al) [22]. Venkataraman (2000) states entrepreneurship as the culmination of how, whom and post effects where products are evaluated and nurtured with constant endeavors (Dimov 2007). Kuratko (2009) realizes that entrepreneurship harnesses energy towards creative goal seeking through effective venture capitals, resource mobilization and opportunity realization. Sarasvathy (2001) points towards disruptive innovation paradox in discontinued focus on wealth generation. Prahalad (1986) developed on the concept of dominant logic which again revolves around the behavioral mindset towards accomplishment of goals [23]. Thus, was created the behavioral logic coming out of the firm (Cyert 2005). According to the study of Emami (2004) the intrapreneurial mindset generation is a wide cognitive arena with greater scope to implementation within organization [24]. 


\section{Materials and Methods:}

\subsection{Participants and procedure}

The sample of the research consists of the employees of companies that have an innovative vision and have already received the innovation award given by the Chamber of Commerce in their region. A total of 235 private sector employees aged older than 21 years, completed a paper-and-pencil questionnaire. The survey was promoted by the research team in different factories via handing out the questionnaires to employees. All the participants were informed about the details of the study and that participation was anonymous and voluntary. Participants' informed consent was taken before they fill out the questionnaire.

\subsection{Measures}

Demographics: Participants first answered demographic questions indicating their age $(1=$ between 21 and 30 years, 2 = between 31 and 40 years, $3=$ between 41 and 50 years, $4=$ older than 51); education level ( $1=$ high school or less, $2=2$ years university, $3=$ bachelor's degree, 4 = master's degree or more; position $(1=$ employee, $2=$ supervisor, $3=$ expert (engineer, $4=$ manager); working time in the same company $(1=1-3$ years, $2=4-6$ years, 3 $=7-10$ years, $4=$ more than 10 years $)$; total working experience $(1=1-3$ years, $2=4-6$ years, $3=7-10$ years, $4=$ more than 10 years).

Intrapreneurship: The scale of the research "How about measuring intrapreneurship" conducted by Jarna and Kaisu in Finland in 2005 was used to assess intrapreneurship. The concept of intrapreneurship was tried to be measured with 39 items in total. Participants rated the items ranging from $1=$ "absolutely disagree" to $5=$ "absolutely agree". However, in the survey, there are also the dimensions of;

- encouragement by management and organization

- individual motivation

- transparency, openness and communality

- individual competence

- enabling working environment

- encouragement to innovations

- development which we define as sub-dimensions of internal entrepreneurship.

The reliability coefficient was adequate in the present study (Cronbach's $\alpha=.88$ ).

Innovation: The scale of the research " Intrapreneurship Modeling in Transition Economies: A Comparison of Slovenia and United States" conducted by Bostjan Antoncic and Robert D. Hisrich in 2000 was used to assess innovation. The concept of innovation was tried to be measured with 13 items in total. Participants rated the items ranging from $1=$ "not important" to 5 = "very important". The reliability coefficient was adequate in the present study (Cronbach's $\alpha=.93$ ).

\subsection{Result}

In the results, the reliability of the survey form was tested, and the sub dimensions of the intrapreneurship were determined. Later, the relationship between the concept of intrapreneurship and the sub-dimensions of intrapreneurship with the concept of innovation has been revealed.

A total of 235 valid survey forms were obtained as a result of the study. The statistical results regarding the demographic data, in other words, the control variables of these surveys are given in Table 1 below. 
Table 1. Demographic Findings on the Employee

\begin{tabular}{|c|c|c|c|c|c|}
\hline Positions & $\mathbf{n}$ & $\mathbf{\%}$ & Time Worked in the Business & $\mathbf{n}$ & $\mathbf{\%}$ \\
\hline Employee & 123 & 52,4 & $1-3$ years & 79 & 33,7 \\
\hline Supervisor & 39 & 16,6 & $4-6$ years & 66 & 28,0 \\
\hline Expert (Engineer) & 24 & 10,2 & $7-10$ years & 32 & 13,6 \\
\hline Manager & 49 & 20,8 & 10 years and above & 58 & 24,7 \\
\hline Educational Background & $\mathrm{n}$ & $\%$ & Total Time Worked & $\mathrm{n}$ & $\%$ \\
\hline High School or less & 54 & 23,0 & $1-3$ years & 65 & 27,7 \\
\hline 2 years university & 35 & 14,9 & $4-6$ years & 69 & 29,4 \\
\hline Bachelor's Degree & 122 & 51,9 & $7-10$ years & 32 & 13,6 \\
\hline Master's Degree or more & 24 & 10,2 & 10 years and above & 69 & 29,3 \\
\hline Age & $\mathrm{n}$ & $\%$ & & & \\
\hline $21-30$ & 110 & 46,8 & & & \\
\hline $31-40$ & 87 & 37,0 & & & \\
\hline $41-50$ & 22 & 9,4 & & & \\
\hline 51 and above & 16 & 6,8 & & $\mathbf{2 3 5}$ & $\mathbf{1 0 0}$ \\
\hline Total & $\mathbf{2 3 5}$ & $\mathbf{1 0 0}$ & Total & & \\
\hline
\end{tabular}

Source: Author Generated Table.

When demographic data are examined, it can be seen that the participants were mostly between the ages of 21 and 40 and the rate was around $84 \%$. Considering the distribution of the employees in terms of their education level; $77 \%$ of them are higher education graduates. When it looked at the distribution of employees as a result of their positions in the business, it was seen that a large part of $52 \%$ were employee working in departments within the organization. Others work in the position of expert or manager according to their field.

When the work experience of the participants in the same organizations, it was determined that $34 \%$ of the majority worked between $0-3$ years. Here, it is seen that a significant rate of $62 \%$ has continued to work in their organizations for $0-6$ years. Considering the total professional work experience of the employees; It is seen that $57 \%$ of them have 0-6 years of total work experience.

Croncbach's Alpha test was applied separately using the SPSS program to the scales related to the cases of 'internal entrepreneurship' and 'innovation' in the survey form. Reliability analysis results for these scales are included in the tables below.

Table 2. Reliability, Average and Standard Deviation Values

\begin{tabular}{|c|c|c|c|c|}
\hline & $\mathbf{N}$ & Average & Std. Deviation & Sig. \\
\hline Intrapreneurship & 39 & 4,30 & 15,907 & 0,884 \\
\hline Innovation & 13 & 4,02 & 10,449 & 0,931 \\
\hline
\end{tabular}

Source: Author generated table.

In the table above, it can be seen that the alpha value showing the reliability coefficients of intrapreneurship and innovation scales is over 0.6 and has an acceptable value for research.

Multiple linear regression analysis was applied to the variables put forward to test the hypotheses developed. The concept of intrapreneurship, which is claimed to have a decisive effect on innovation in regression analysis, is taken as an independent variable and innovation as a dependent variable. Table 3 contains the results of the regression analysis between the concept of intrapreneurship and innovation.

Table 3. The Relationship Between Intrapreneurship and Innovation

\begin{tabular}{|l|l|l|l|l|l|l|}
\hline Model & B & Std. Error & & Beta & t & Sig. \\
\hline
\end{tabular}




\begin{tabular}{|c|c|c|c|c|c|c|}
\hline Constant & 2,081 & 0,397 & & & 5,240 & 0,000 \\
\hline Intrapreneurship & 1,416 & 0,092 & & 0,711 & 15,444 & 0,000 \\
\hline \multicolumn{7}{|c|}{$\mathrm{R}=0,711$} \\
\hline
\end{tabular}

Source: Author generated table.

In this analysis, $\mathrm{R}=0.711$ is obtained when the relationship between the independent variable of intrapreneurship and the dependent variable of innovation is examined. When the test results on the significance of regression coefficients are examined, it is seen that the level of intrapreneurship has an important determinant on innovation.

In regression analysis, the sub-dimensions of intrapreneurship, which are claimed to have a decisive effect on innovation, are taken as independent variable and innovation as dependent variables. Table 4 contains the results of multiple regression analysis between subfactors of intrapreneurship and innovation.

Table 4. The Relationship Between Sub-Factors od Intrapreneurship and Innovation

\begin{tabular}{|c|c|c|c|c|c|}
\hline Model & B & $\begin{array}{c}\text { Std. } \\
\text { Error }\end{array}$ & Beta & t & Sig. \\
\hline Constant & 2,004 &, 405 & & 4,953 &, 000 \\
\hline F1: encouragement by management and org. &, 332 &, 091 &, 233 & 3,651 &, 000 \\
\hline F2: individual motivation &, 258 &, 076 &, 193 & 3,401 &, 001 \\
\hline F3: transparency and openness &, 165 &, 086 &, 122 & 1,920 &, 056 \\
\hline F4: individual competence &, 195 &, 064 &, 182 & 3,027 &, 003 \\
\hline F5: enabling working environment &, 075 &, 070 &, 052 & 1,061 &, 290 \\
\hline F6: encouragement to innovations &, 434 &, 087 &, 260 & 4,995 &, 000 \\
\hline \multicolumn{7}{|l|}{,- 062} &, 063 &,- 051 &,- 988 &, 324 \\
\hline F7: development $\mathrm{R}=0,749 \mathrm{R}^{2}=0,562$ \\
\hline
\end{tabular}

Source: Author genertaed table

In this analysis, the results are obtained when the relationship between independent and the dependent variable innovation is examined $(\mathrm{R}=0.749)(\mathrm{R} 2=0.562)$. Accordingly, the multiple coefficient determination is 0.562 and $56 \%$ of the innovation is explained by the sub dimensions of intrapreneurship (encouragement by management and organization, individual motivation, transparency and openness, individual competence, enabling working environment, encouragement to innovations, development). In other words, the seven subdimensions, which belong to intrapreneurship, explain $56 \%$ of the total variance on the concept of innovation.

According to the standardized regression coefficient (Beta), the order of the comparable importance of independent variables on the concept of innovation; encouragement by management and organization, encouragement to innovations, individual motivation, individual competence, transparency and openness, enabling working environment and development. When the test results on the significance of regression coefficients are examined, it is seen that only encouragement by management and organization, encouragement to innovations, individual motivation and individual competence variables have an important determinant on innovation. 


\section{Analysis}

There has been various questions arising from previous literature though very few which can answer the myriad pyramids of poverty in society and how intrapreneurial tracking of human actions and indicators of intrapreneurship can challenge the very foundations of economic growth in a society where deprivation and systematic collapse of a nation has seen innumerable deaths, unemployment and rising suicidal cases leave alone the rising barometers of health infrastructural collapse in emerging economies globally. Why and how these particular gaps can be measured? How strong are the forces underlying human necessity to innovate while inside the corporate environment? How can human innovation functionalities and nudges create resilience inside the corporate firms? What exactly intrapreneurial players do to come out of the poverty trap? It is noteworthy to mention that while measuring the intrapreneurial trends and factors affecting the trends; we are somehow dealing with the internal conflicts arising out of Hayekian human actions and how these behavioral nudges are creating far reaching effects on how companies innovate? How innovations create resilience and sustainability? Do intrapreneurial factors of growth are elastic? The behavioral paradox arising out of various social choices wherein humans act creates a long-lasting effect on how companies can deliver and create a top-down approach sustainable developmental strategy plan for its innovation platform. It is important to understand that the global polymath has changed over time and many facets of entrepreneurial activity is being debated globally even the innovation thinking of Adam Smith and his underlying principles of invisible hand where Adam Smith has often been challenged by contemporary economists and frontline strategists. While conceptualizing intrapreneurship we have to do a surgical analysis on various factors like ethics and corporate interventions in creating challenging entrepreneurial dialects in challenging times like the pandemic. Therefore, it is mandatory to study the economic variances in rationality within the firm and how firms react to their employees and subsequent innovating habits and cultures. Analyzing the blackbox of intrapreneurship development it is important to note that innovation management is no more a monopoly statement but requires multidisciplinary approaches of deductive measures like behavioral nudges and how and when people react to changes within and outside a firm. Post measuring the factors to innovation it requires positioning of factors at appropriate levels firm strategists to create innovation ecosystem by choice and preferences during crisis to hasten the product development scenario and create resilience in actions.

\section{Conclusion}

The research is quite unique as it not only addresses the behemoth of wide gaps in behavioral thinking process which affects how and when new entrepreneurs like babies born out of natural conditions are examined inside the corporate firms but also the extrinsic indicators and functionalities where new entrepreneurs thrive and contribute not only to the economics of firms but also improve, nurture and bring about drastic changes to the way a firm operates in a society imparting responsible behaviors for improving livelihood in general. We cannot exclude social innovation and financial inclusion. There needs to be a strategic choice arising out of human developmental thoughts in times of big pandemics like COVID-19 which is quite different in choice and environmental relevance than the Spanish Flu or the Russian Flu.But whatever may be the case underlying changing paradigms in a polarized world, there lies an imperative to change the innovation ambience and create resilient bodies which can improve the measurement of entrepreneurial activity inside a firm. Balancing the irregularities in measuring economics of firm growth requires far reaching commitments and research agenda which are far disciplined in measuring not only quantitatively but 
qualitatively analyzing the human actions and choices humans make which are quite different sometimes with respect to the nature of homoeconomicus or the very own economic man. May be just like the mutant strain in COVID-19 we have encountered the mutant strain in innovation thoughts and rationality behind acting innovatively in corporate entrepreneurial activity. Future implications hover around possible implications of artificial intelligence and big data in playing with the deduction in this research which can be a stable mapping point for policy makers both inside and outside the firm to implement and harness for steady rise of firm revenue and increase visibility in CSR activity with financial inclusion and merits.

\section{References}

1. B. Antoncic, R. D. ve Hisrich, J. Developmental Entrep., 5(1), 21-36 (2000)

2. H. Jarna, K. ve Kaisu, How About Measuring Intrapreneurship? Small Business Institute, Turku School of Economics and Business Administration, Finland (2005)

3. R. Samrat, Vestnik of Astrakhan State Technical University. Series: Economics, 4, 98104 (2020)

4. R. D. Hisrich, Am. Psychol., 45(2), 209-222 (1990)

5. B. Antoncic, R.D. Hisrich, J. Small Bus. Enterp. Dev., 10(1), 7-24 (2003)

6. P.C. Neessen, M. C. Caniëls, B. Vos et al., Int Entrep Manag J, 15, 545-571 (2019)

7. J. Daykin, Intrapreneurship, https://www.forbes.com/sites/jordandaykin/2019/01/08/intrapreneurship/, [Accessed: 02 February 2021]

8. G. III Pinchot, Intrapreneuring: Why You Don't Have to Leave the Corporation to Become an Entrepreneur (1985), https://ssrn.com/abstract=1496196

9. G. III Pinchot, Research Management, 30(2), 14-19 (1987)

10. J. A. Cunningham, E. E. Lehmann, M. Menter, N. Seitz, J. Technol. Transf., 44, 14511475 (2019)

11. C. Carrier, Theory and Practice, 21(1), 5+ (1996)

12. He, Qin, Du Hui, IJISSS 12(1), 1-15 (2020)

13. S. Mullainathan, R. H. Thaler, Behavioral Economics, NBER Working Papers 7948, National Bureau of Economic Research, Inc., (2000)

14. R. H. Thaler, Misbehaving: The making of behavioral economics, (W W Norton \& Co, 2015)

15. R. H. Thaler, S. Benartzi, J. Polit. Econ., 112, S164-S187 (2004)

16. R. H. Thaler, J. Behav. Decis. Mak., 12, 183-206 (1999)

17. S. Ray, D.Y. Leandre, Int. Res. J., 6(96) Part 4, 53-56 (2020)

18. K. Reuther, E. P. Borodzicz, C. Schumann, Identifying Barriers to Intrapreneurship, in Proceedings of IEEE International Conference on Engineering, Technology and Innovation (ICE/ITMC), 17-20 June 2018, 1-9, Stuttgart, Germany (2018)

19. T. Chahine, Front. Public Health, 9, 593553 (9 Apr. 2021)

20. B. Aulet, Disciplined Entrepreneurship, (Wiley, 2013)

21. JG Dees, The Meaning of Social Entrepreneurship, (2001), https://centers.fuqua.duke.edu/case/wpcontent/uploads/sites/7/2015/03/Article_Dees_MeaningofSocialEntrepreneurship_2001 .pdf, [Accessed: 20 April 2021) 
22. A. Sen, J. Drèze, India: Development and Participation, (New Delhi, India: Oxford University Press, 2002)

23. M. von Kutzschenbach, C.-H. Daub, Digital Transformation for Sustainability: A Necessary Technical and Mental Revolution, in book: New Trends in Business Information Systems and Technology, (Publ.: Springer, Cham) (2021)

24. E. Okada, Urban Resilience and Opportunity Identification of Social Entrepreneurs, in book: Management of Science-Intensive Organizations, Palgrave Macmillan, Cham, (2021) 